\title{
Seroprevalence of toxoplasmosis in women with repeated abortions in Kashmir
}

\author{
Abdul Hamid Zargar, Shariq Rashid Masoodi, Bashir Ahmed Laway, Bashir Ahmed Sofi, \\ Arshad Iqbal Wani
}

\begin{abstract}
Toxoplasmosis caused by an obligate intracellular protozoan parasite Toxoplasma gondii is a very common infection among young adults in different parts of the world. ${ }^{1}$ Most of the toxoplasma infections are asymptomatic, the diagnosis relies mainly on the results of serological tests. The clinical implications of toxoplasma infection in pregnant patients are manifold. Such patients may have spontaneous abortions, still births or premature delivery in addition to various fetal anomalies. ${ }^{2}$ Ideally every woman should know her toxoplasma status before conception. Toxoplasma antibodies may persist in the serum of an asymptomatic people for years at higher titres. ${ }^{3}$ In this study we screened women with repeated abortions for prevalence of toxoplasma antibodies ( $\operatorname{IgM})$ to determine any possible aetiological relation between abortions and toxoplasma infection.
\end{abstract}

\section{Methods}

Two hundred and eighty five consecutive women who attended our endocrine clinic at Institute of Medical Sciences, Soura, Srinagar, for repeated abortions (two or more) were studied for serological evidence of toxoplasmosis in the form of IgM antibodies. Abortion was defined as the termination of pregnancy before 20 weeks of gestation or below a fetal weight of 500 grams. ${ }^{4}$ One hundred and sixty nine, age matched, multiparous controls were also studied simultaneously. To ensure a uniform socioeconomic group, all the controls were selected randomly from subjects attending the asso-

ccepted for publication 30 September 1997 ciated Maternity Hospital of the Institute for routine antenatal and postnatal visits. In 62 controls, blood samples for IgM toxoplasma were taken in immediate postpartum period while in the 107 controls samples were taken during pregnancy. These 107 subjects subsequently had normal deliveries. The serum samples were separated and stored in aliquots at $-10^{\circ} \mathrm{C}$ till assayed. Samples were tested for toxoplasma IgM by ELISA kits, commercially available from Diagnostic Automation Inc, Calabasas, California, USA. Samples were tested strictly according to the manufacturer's instruction. The results are read by a microwell reader compared in a parallel manner with calibrator and controls.

\section{INTERPRETATION}

Toxo $M$ index of less than 0.80 is taken as negative, between 0.80 to 1.00 is equivocal, and 1.00 or greater is positive for IgM antibody to Toxoplasma gondii and indicates the probability of current or recent toxoplasmosis.

Statistical analysis included standard methods for rates and proportions and comparison among variables. A two tailed $p$ value was used for calculating statistical significances. A p value of $<0.05$ was taken statistically significant.

\section{Results}

This study included 285 women with repeated abortions and 169 control subjects. Table 1 shows the baseline characteristics of the two groups. There was no significant difference in mean age and parity of the abortion group and control group. The number of pregnant subjects in the abortion group was 155 $(54.38 \%)$ compared with $107(63.37 \%)$ in the control group. The number of abortions ranged between two and five (mean (SD) 2.39 (0.75); median, 2). Forty eight per cent of the abortions had occurred in first trimester, 36 per cent had occurred in second trimester, and 16 per cent had occurred in third trimester. Of 285 women with repeated abortions, 141 $(49.47 \%)$ serum samples were positive for IgM toxoplasma antibody, two $(0.70 \%)$ were equivocal, while $142(49.82 \%)$ were negative. In contrast, only $15(8.88 \%)$ serum samples were positive for IgM toxoplasma antibody in 169 controls. Thus seroprevalence of toxoplasma IgM antibodies was significantly more in women with repeated abortions than in control subjects $(\mathrm{p}<0.001)$. Table 2 shows seroprevalence of IgM toxoplasma in pregnant and non-pregnant cases within each group. 


\section{Discussion}

The exposure of Toxoplasma gondii most commonly results in an asymptomatic infection. The protozoan parasite is transmitted to humans by ingestion of the tissue cysts in raw or undercooked meat, particularly lamb and pork, or contact with cat faeces. ${ }^{3}$ The clinical implications of toxoplasma infection in pregnant patients are manifold. Such patients may have spontaneous abortions, stillbirth, premature delivery or fetal anomalies. Intrauterine transmission occurs in approximately $25 \%$, $54 \%$, and $65 \%$ of untreated women who develop acute toxoplasmosis during the first, second, and third trimesters respectively. Specific maternal therapy can reduce the overall incidence of fetal infection by $50 \%$. Fetal involvement is most severe when maternal infection is contracted early in pregnancy. ${ }^{5}$ The extent to which toxoplasmosis causes habitual abortion is still controversial. ${ }^{6}$ This study was carried out in 285 cases of repeated abortions, and 169 multiparous women (107 pregnant and 62 non-pregnant) as controls. Tests for presence of toxoplasma IgM antibody were done for both groups. We found a high prevalence of $\operatorname{IgM}$ antibody against Toxoplasma gondii in women with repeated abortions $(49.47 \%)$ compared with controls $(8.88 \%)$ who did not have history of abortions. This suggests a possible causal relation between Toxoplasma gondii and repeated abortions. However, there are no other data about the seroprevalence of toxoplasmosis in this area of the world, which would give more power to our study. The occurrence of toxoplasma infection is common through out the world. The prevalence of toxoplasma antibodies ranges from $5 \%$ to $95 \%$ among young adults in different parts of the world. ${ }^{1}$ According to one estimate, over 500 million humans around the world are infected with Toxoplasma gondii and various studies from France, United States, and United Kingdom have shown an approximate prevalence of toxoplasmosis in $90 \%, 20-70 \%$, and $30 \%$ respectively. ${ }^{2}$ In pregnant women worldwide, there are seroprevalences of toxoplasmosis from $7 \%$ to $51.3 \%$ and in women with abnormal pregnancies and abortions the seroprevalences vary from $17.5 \%$ to $52.3 \% .^{7}$ In an Indian study toxoplasmosis was found in $38 \%$ of women with complete abortion. ${ }^{8}$ In many other studies high prevalence of toxoplasmosis was reported in subjects with repeated abortions. ${ }^{9}$ However, some other studies have negated the role of toxoplasmosis in habitual abortions. ${ }^{10} \mathrm{~A}$ study to associate toxoplasmosis with recurrent abortions is difficult because a large cohort of women with toxoplasmosis would be needed to assess the incidence of otherwise unexplained recurrent abortions in them compared with controls.

The final host of Toxoplasma gondii is the domestic cat. Flies and cockroaches may act as transport hosts. ${ }^{3}$ Here in Kashmir, cats are innumerable, mainly as strays. The climate is temperate and may favour the survival of oocysts. Probably the transmission of toxoplasma infection in this area results from the ingestion of oocysts or the tissue cysts in the raw or uncooked meat, particularly sheep and goat meat and contaminated vegetables. In view of the high prevalence of Toxoplasma gondii in our subjects with repeated abortions it is recommended that every woman of reproductive age who has history of abortion should be tested for her toxoplasma serological status before next conception and treated accordingly. Women with negative serological tests are at risk of acquiring a primary infection during pregnancy and education regarding preventive measures should be provided to them.

1 Stagno S. Congenital toxoplasmosis. Am $\mathcal{f}$ Dis Child 1980;134:635-7.

2 Jani RH, Dave $M$. Toxoplasma infection: a perspective Indian f Intern Med 1994;4:36-6.

3 Yaneza A, Kumari P. Prevalence of toxoplasma antibodies in blood donors in Al-Hassa. Annals of Saudi Medicine 1994;14:230-2.

4 Speroff L, Glass RH, Kase NG. Clinical gynecologic ndocrinology and infertility. Baltimore: Williams and Wilkins, 1989:535.

5 Freij BJ, Sever JL. Toxoplasmosis. Pediatr Rev 1991;12:22736.

6 Sahwi SY, Zaki MS, Haiba NY, el-Said OK, Anwar MY, Abd-Rabbo SA. Toxoplasmosis as a cause of repeated abortions. F Obstet Gynaecol 1995;21:145-8.

7 Galvan-Ramirez-M-de-la L, Soto-Mancilla JL, VelascoCastrejon O, Perez-Medina R. Incidence of antitoxoplasma antibodies in women with high risk pregnancy and habitual abortion. Rev Soc Bras Med Trop 1995;28: and habit.

8 Mookherjee N, Gogate A, Shah PK. Microbiological evaluation of women with bad obstetric history. Indian $\mathcal{F}$ Med Res 1995;101:103-7.

9 Attia RA, el-Zayat MM, Rizk H, Motawea S. Toxoplasma IgG and IgM antibodies. A case control study. 7 Egypt Soc Parasitol 1995;25:877-82.

10 Djurkovic-Djakovic O. Toxoplasma infection and pathological outcome of pregnancy. Gynecol Obstet Invest 1995;40: $36-41$ 